\title{
Considering Strengthening the Enrollment Work of Adult Higher Education of Correctional Police Institutes
}

\author{
Guofu Fan \\ The Central Institute for Correctional Police, Hebei University \\ No.103 Qiyi Midway Road, Baoding 071000, Hebei, China \\ E-mail: fanguofu@163.com
}

\begin{abstract}
This text tries to explore the problem of the enrollment work of adult higher education of correctional police institutes in five aspects in order to offer some help for promoting the steady, healthy and coordinated development of adult education enrollment of higher education.
\end{abstract}

Keywords: Correctional police institute, Enrollment of adult Higher Education

The enrollment of adult higher education is an important part of the correctional police institutes. It has played a vital role in building a harmonious society and providing services for judicial administration. The work directly determines the quality of the students who are enrolled and decides whether the people cultivated can qualify for the justice system or not. At the same time, it is also an indispensable factor that can affect the survival and development of adult higher education of the judicial police institutes. Therefore, in order to achieve the objective of constructing a life-long educational system and establishing a learning society, corresponding reforms or innovations must be carried on of the enrollment of the adult higher education of the judicial institutes in order to promote the cause of adult higher education institutions of the correctional police institutes a steady, healthy, and coordinated growth.

1. Providing the effective service for the grass-root units of the judicial administrative system to promote social harmony and stability

Mrs. Wu Aiying, the Minister of Justice, once delivered an important speech at the national conference of the administration of justice on building grass-roots of judicial administration. She stressed that strengthening the grass-root building of administration of justice is a major task of the whole situation of China and the CPC, and the overall development of the cause of the administration of justice. The vice Minister of Justice, Fan Fangping, in his concluding remarks at this conference explicitly called on that the judicial administrations at all levels should offer services for the grass roots, helping them solve the difficulties in practice. And the factual results of helping the grass root units to strengthen the infrastructure and operations would become the important measurement of evaluating the judiciary administrative organs and leading cadres. As far as the judicial police colleges or institutes are concerned, in order to carry out the requirements of the Ministry of Justice, they must closely integrate their own characteristics and make full use of their advantages to offer services for the grass roots in the aspects of theory, personnel, techniques and education etc. Among them, the adult education enrollment can adopt various preferential measures for the workers or officials or their children of this system to receive further schooling, thus arousing the enthusiasm of the grass root staff, as will contribute to social harmony and stability.

2. Adapting to the characteristics of the administration of the justice system especially the work of the correctional system and greatly developing the correspondence and part-time education

The Ministry of Education in document No. 11 in 2005 of the Teaching and Learning Section, Notice for working out the plan of enrollment of the national adult higher education for every province in 2005, clearly prescribed that, "Each adult higher school in the process of making the sub-provincial plans, should fully demonstrate the characteristics of the adult higher education of providing services for people in working position and studying in spare time. The scale of full-time students should be reduced as far as possible. Colleges and universities should not exceed $15 \%$ of the enrollment. Foreign languages institutes should not exceed 30\%. Independent adult higher schools, the Western medicine and the Arts schools should not exceed 50\%.” 
From the practice of the administration of justice system, especially the work of the prison education through labor system, after the personnel system reform, it is an indisputable fact that the number of staff is significantly reduced but heavy workload and great pressure begin to appear. Under this working situation, it becomes more difficult for the workers, particularly the prison inmates off their duty to get a full-time learning. Therefore, the judicial police institutes must adhere to the scientific outlook on development, change the old view of weighing the fulltime education while looking down upon the part-time education, vigorously develop the correspondence and part-time courses. Continually expanding the scale of correspondence and part-time courses is not only the future tendency of development but also meets the requirements of the Ministry of Education, as well as the administration of justice system, particularly the practical needs of the prison re-education system.

\section{Strengthening the propaganda work of enrollment and continuing widening the students' sources}

Adult higher education and its enrolling objects are of characteristic of sociality, universality and diversity, which makes the adult education enrollment more important and complicated. Statistics shows that in the past two or three years, the number of adult students who take part in the undergraduate examination has been decreased sharply by more than $20 \%$ a year. And those who apply for junior college education has been declined even by $30 \%$. The appearance of this phenomenon is against the development objective of the higher education for adults. It does not only seriously affect the survival and development of higher education for adults, but also causes a great waste of educational resources. In this context, undoubtedly it is necessary to strengthen the enrollment. Considering that the judicial institutes on the very beginning was on the way of opening schools merely within the judicial system, when beginning to turn to the whole society for enrollment, they have little popularity and less influence. Even some grass-root units or work people in remote areas in the judicial system have also known little about the education. Therefore, the judicial colleges must adopt varieties of measures. Recruitment pamphlets, Internet, television or radio, newspapers or magazines all can be used to carry out an effective propaganda. Standardization must be continuously strengthened to make the judicial colleges known by every household to win the candidates and their families understanding and support so as to enhance the publicity and broaden the channels for new candidates.

\section{Speeding up the reform of school system of the judicial adult higher education and changing the academic year system into credit system}

The current adult higher educational system of judicial institutes has stringent requirements for the school system of the university or college students, which is not in line with the adult features. If the school system is changed into credit system, the year or time of study is not fixed, and students can be allowed to advance or delay their graduation, the contradictions between work and study can be greatly relieved. For those students who have to stop their studies can be allowed to leave midway and to continue their studies if they want to in the specified time. Their original acquisition of the credits will be still valid. The credits that those students who are still in their work position have acquired at other universities can be acknowledged according to some relevant provisions. Within a certain scope students can choose the enrolling time, the learning form or the curriculum as they like. And there will be many forms of certificates, professional proofs, professional qualifications or courses certificates to be chosen from and other certification system, etc. This credit system is in line with the spirit of building a life-long educational system and establishing a learning society.

\section{Meeting the challenges from learning society and strengthening the theoretical study of adult education enrollment work}

The appearance of the theory of the learning society leads to a major change in the old philosophy of education. In order to meet various challenges from the learning society and promote the healthy, orderly and effective development of the administration of justice, the enrollment work of adult higher education in the judicial schools must start from the work needs of the judicial administration especially the prison and labor education administration system, center around the theoretical issues of the adult higher education enrollment, effectively strengthen the forward-looking and strategic theoretical research, further broaden the scope of thinking, constantly adjust the specialty structure to flexibly, and diversely and effectively promote the development of higher education for adults.

In conclusion, in the process of building a life-long education system and establishing a learning society, the enrollment work of adult higher education in the judicial schools, which shoulders an important mission, must adapt itself to the social development and changes, keep up with the times, take the scientific outlook on development as guidance and reform in many aspects in order to help more learners, especially those from the judicial system administration (including the prison and reeducation system) to achieve their dream of studying at any time in any places, and to be able to find the study content and learning methods for themselves and for the need of the judicial administration. 


\section{References}

Cong, Kai. (2005). Several opinions of the propaganda of the higher education. Qiqihar Medical Journal.

$\mathrm{Li}$, Hong, and Li, Yongzhong. (2005). China's reform on enrollment system of adult higher schools guided by the scientific outlook on development. Contemporary Educational Forum.

Li, Xiuwen. (2005). Perfecting the propaganda of adult education enrollment. Adult education, October.

Liu, Wenying. (2005). Exploring the reform of the adult education in the context of a learning society. Huaiyin Institute of Technology, Vol. 14.

Ma, Songting. (2005). On the enrollment system of adult higher education. Chinese Adult Education.

Tang, Guohua. (1996). Considering deepening the reform of adult education enrollment. Jiangsu Higher Education.

Xiong, Yuanxiang. (2004). Why does entrance examination for adults encounter cold tide. Chutian City Daily.

Zeng, Yulin. (2005). Considering the enrollment system of adult higher education in the context of a learning society. Education and Occupation. 